Research Article

\title{
Use of over the counter drugs in urban and rural populations of Mandya district: a cross-sectional study
}

\author{
Nagarajaiah B. Hanumantharayappa*, Shashikumar N. Siddaiah
}

Department of Pharmacology, Mandya Institute of Medical Sciences, Mandya, Karnataka, India

Received: 07 June 2016 Accepted: 04 July 2016

\section{*Correspondence to:}

Dr. Nagarajaiah B.

Hanumantharayappa, Email: magadinagarajaiah@ gmail.com

Copyright: (C) the author(s), publisher and licensee Medip Academy. This is an openaccess article distributed under the terms of the Creative Commons Attribution NonCommercial License, which permits unrestricted noncommercial use, distribution, and reproduction in any medium, provided the original work is properly cited.

\begin{abstract}
Background: Over-the-counter (OTC) drugs are medicines which are sold directly to a consumer without a prescription. There is a big potential for misuse and abuse of such products. Over the counter (OTC) drugs are meant for selfmedication and are of proved efficacy and safety. Their improper use and unable to follow the precautions due to lack of knowledge of their side effects and interactions could lead to serious complications, especially in children and elderly.

Methods: This cross-sectional study was conducted using a pre-tested \& semistructured questionnaire. A total of 400 urban and 400 rural persons were interviewed for this study. 100 persons were interviewed in Mandya city and 50 each from the city in each of the 6 taluks. Data was entered in Microsoft Excel software and was analysed using Statistical Package for Social Sciences (SPSS) software. Chi-square test was used to calculate the difference in use among the urban and rural OTC drug users.

Results: A total of 800 persons were interviewed regarding their use of OTC drugs, among them 400 were urban residents and 400 were rural residents of Mandya district. Of the 400 urban persons and rural persons, 310 respondents $(77.50 \%)$ and 273 respondents $(68.25 \%)$ reported the use of OTC in the recall period of the last 6 months respectively. The difference in the usage of OTC by urban adults was significantly more than that of rural adults.

Conclusions: The proportion of the respondents who had practiced selfmedication with OTC drugs is very high. The prevalence of self-medication with OTC drugs in our study was found to be $72.87 \%$ and is nearly same in both rural and urban population. As this study was conducted in a limited population in Mandya district, generalization of the study to all the population cannot be done, and it requires large study in all districts of Karnataka with adequate sampling methods.
\end{abstract}

Keywords: OTC drugs, Self-medication, Questionnaire

\section{INTRODUCTION}

Over-the-counter (OTC) drugs are medicines sold directly to a consumer without a prescription, from a healthcare professional, as compared to prescription drugs. In many countries, regulatory agencies select the OTC drugs to ensure that they are safe and effective when used. OTC drugs are usually regulated by active pharmaceutical ingredients, not the final products. By regulating APIs governments allow manufacturers freedom to combinations of ingredients or formulate ingredients into proprietary mixtures. ${ }^{1}$
Self-medication has an important role to play in healthcare. With improvement in people's general knowledge, education and socio-economic status, selfmedication has been successfully integrated into many health care systems throughout the world. Selfmedication products are those that do not require a medical prescription and that are produced, distributed and sold to consumers. Self-medication with OTC drugs responsibly can be used to prevent and treat ailments that do not need medical consultation. This reduces pressure 
on medical services, when these are limited, especially for those populations living in rural or remote areas where access to medical services may be difficult. Patients are able to control their own conditions to a greater extent. ${ }^{2}$ The factors contributed to prescription drugs being deregulated to over-the-counter (OTC) sale and new drugs with specific pharmacological action have been successfully reclassified from prescription to nonprescription status in many countries. For example, in the United States of America, products containing over 80 active ingredients of different therapeutic groups were switched from prescription-only to OTC status between 1976 and 2000. In many cases, restrictions imposed on reimbursement of prescription drugs have provided the impetus for authorities to evaluate and deregulate selfmedication products to OTC status. ${ }^{2}$

Recent development of the many pharmaceutical companies contribute to a wide spread availability of OTC Medicine. ${ }^{3}$ There is also the potential for misuse and abuse of such products is increased over the counter (OTC) drugs are meant for self-medication and are of proved efficacy and safety, their improper use and unable to follow the precautions due to lack of knowledge of their side effects and interactions could have serious implications, especially in extremes of ages (children and old age) and special physiological conditions like pregnancy and lactation. ${ }^{4-7}$ There is always a risk of interaction between active ingredients of hidden preparations of OTC drugs and prescription medicines, as well as increased risk of worsening of existing disease pathology. ${ }^{8}$ As no study was undertaken, regarding the use of 'over the counter' drugs in urban and rural populations of Mandya district, it was proposed to conduct this study, to assess the prevalence and pattern of use of OTC drugs among the urban and rural population of Mandya. The objective of this study was to determine the prevalence of use of OTC drugs in Mandya district and to determine the differences in the use of OTC drugs in urban and rural areas of Mandya district.

\section{METHODS}

This cross-sectional study was conducted using a pretested and semi-structured questionnaire. Study subjects consisted of adults residing in urban and rural areas of Mandya district who gave informed consent to participate in the study. A total of 400 urban and 400 rural persons were interviewed for this study. 100 persons were interviewed in Mandya city and 50 each from the city in each of the 6 taluks. An equal number of persons were interviewed in each ward of the cities. 2 villages were randomly selected in each of the 7 taluks. About 30 people were interviewed in each selected village. Data was entered in Microsoft Excel software and was analysed using statistical package for social sciences (SPSS) software. Chi-square test was used to calculate the difference in use among the urban and rural OTC drug users.

\section{RESULTS}

A total of 800 persons were interviewed regarding their use of OTC drugs, among them 400 were urban residents and 400 were rural residents of Mandya district. Of the 400 urban persons and rural persons, 310 respondents $(77.50 \%)$ and 273 respondents $(68.25 \%)$ reported the use of OTC in the recall period of the last 6 months respectively. The difference in the usage of OTC by urban adults was significantly more than that of rural adults at $95 \%$ significance level. (chi-square value $=8.657, \mathrm{p}$ value $=0.0032$ ).

Table 1: Differences in the use of OTC drugs in the different socio-demographic groups belonging to urban and rural areas of Mandya district.

\begin{tabular}{|lllll|}
\hline & Urban $(\%)$ & Rural $(\%)$ & chi-square value & P value \\
\hline Total & $310(77.50)$ & $273(68.25)$ & 8.657 & 0.0032 \\
\hline Sex & & & 0.449 \\
\hline Male & $171 / 209(81.82)$ & $176 / 223(78.92)$ & 0.571 & 0.00032 \\
\hline Female & $139 / 191(72.77)$ & $97 / 177(54.80)$ & 12.9 & 0.606 \\
\hline Age group & & & 0.000218 \\
\hline $18-40$ & $109 / 166(65.66)$ & $108 / 158(68.35)$ & 0.265 & 0.00624 \\
\hline $41-60$ & $135 / 159(84.90)$ & $109 / 162(67.28)$ & 13.67 & 0.0030 \\
\hline$>60$ & $66 / 75(88.00)$ & $56 / 80(70.00)$ & 7.48 & 0.6526 \\
\hline Education & & & & 0.0481 \\
\hline Primary or less & $93 / 114(81.57)$ & $101 / 155(65.16)$ & 8.805 & 0.2026 \\
\hline High school & $100 / 132(75.76)$ & $119 / 162(73.45)$ & 3.906 & \\
\hline College & $117 / 154(75.97)$ & $53 / 83(63.85)$ & & \\
\hline
\end{tabular}


While the proportion of males taking OTC drugs was slightly higher in urban areas, the difference was not statistically significant. It was found that the usage of OTC drugs was significantly more among urban females as compared to rural females. $80.32 \%$ males used OTC while $64.13 \%$ females used OTC. The difference was statistically significant. In urban areas, usage of OTC drugs was more in the age groups $40-60$ years and above 60 years as compared to the $18-40$ age groups. In the rural areas there was no significant difference in OTC usage among the different age groups. With regard to the urbanrural differences, usage of OTC drugs was significantly more in the age groups 40-60 years and above 60 years residing in urban areas. Primary educated persons used more OTC drugs in urban areas as compared to high OTC drug usage among high school educated in rural areas. Significantly higher usage was found in primary and college educated urban population as compared to their rural counterparts.

Table 2: Types of OTC drugs used by urban and rural people of Mandya district.

\begin{tabular}{|llll|}
\hline & Urban $(\%)$ & & Rural \%) \\
\hline Analgesics & $201(68.84)$ & Analgesics & $166(60.81)$ \\
\hline Antipyretics & $128(41.29)$ & Antipyretics & $125(45.79)$ \\
\hline Antihistamines & $117(37.74)$ & Antacids & $104(38.10)$ \\
\hline Antacids & $99(31.94)$ & Antihistamines & $93(34.07)$ \\
\hline Antibiotics & $85(27.42)$ & Antispasmodics & $41(15.02)$ \\
\hline Antidiarrheals & $64(20.65)$ & Antidiarrheals & $29(10.62)$ \\
\hline Antispasmodics & $22(7.09)$ & Antibiotics & $23(8.43)$ \\
\hline Total & $\mathbf{3 1 0}$ & Total & $\mathbf{2 7 3}$ \\
\hline
\end{tabular}

In urban areas, the most common medications for which OTC drugs were consumed were for aches and pains $(68.84 \%)$ followed by fever $(41.29 \%)$. The top two symptoms for usage of OTC drugs were the same in rural areas also. Medications for cold and allergy (37.74\%) and for gastritis $(31.94 \%)$ were the next common reasons in urban areas. In rural areas the third and fourth common reasons for OTC usage was gastritis $(38.10 \%)$ and cold and allergy (34.07\%). Antibiotic $(27.42 \%)$ and antidiarrheal $(20.65 \%)$ OTC drugs were more common in urban areas as compared to rural areas $(8.43 \%$ and $10.62 \%$ respectively). Antispasmodics were used more in rural $(15.02 \%)$ than in urban $(7.09 \%)$ areas.

Table 3: Reasons for usage of OTC drugs in urban and rural area in the study subjects.

\begin{tabular}{|llll|}
\hline & Urban (\%) & & Rural (\%) \\
\hline Easy availability & $174(56.13)$ & Cost effective & $198(72.53)$ \\
\hline Avoid consultation & $129(41.61)$ & Lack of doctor & $166(60.81)$ \\
\hline Cost effective & $117(37.74)$ & Saves time & $145(53.11)$ \\
\hline Saves time & $70(22.58)$ & Easy availability & $87(31.87)$ \\
\hline Avoid lab investigation & $41(13.23)$ & Avoid consultation & $54(19.78)$ \\
\hline Lack of doctor & $17(5.48)$ & Avoid lab investigation & $19(6.96)$ \\
\hline Total & $\mathbf{3 1 0}$ & Total & $\mathbf{2 7 3}$ \\
\hline
\end{tabular}

The top two reasons for the usage of OTC drugs in urban areas was its easy availability and the drugs could be procured circumventing the process of doctors' consultation. In rural areas, the reasons were that it was cheap, as they need not pay consultation fees and the availability of doctors for consultation was limited. The people of rural areas used the free consultation and free drugs available at PHCs wherever available but depended on OTC where the benefits of PHCs were absent. Cost effectiveness and time saving were the third and fourth reasons for use of OTC drugs in urban areas while in rural areas it was saving time (as in the time spent to travel long distances to get doctors consultation) and the fact that they could get the drugs without consultation.

\section{DISCUSSION}

The use of self-medication with OTC drugs is widespread all over the world, especially urban and educated population. ${ }^{9,10}$ The proportion of the respondents who had 
practised self-medication with OTC drugs is very high. This is indeed alarming in view of the possible hazards associated with such practice. The prevalence of selfmedication with OTC drugs in our study was found to be $72.87 \%$ and is nearly same in both rural and urban population. This study also indicated low knowledge about dose, duration, side effects, and drug interactions of commonly used drugs in accordance with reports of the previous studies. ${ }^{11,12}$ Irrational use of drugs may lead to accidental drug poisoning. There is always a chance of using expired drugs, sharing them with friends or taking medicine that have been originally prescribed for some other problem. Other problems related to self-medication are wastage of resources and serious health hazards such as drug dependence, adverse reaction, and prolonged suffering.

Previous studies in India have shown that the prevalence of self-medication was $37 \%$ in urban population and $17 \%$ in rural population, whereas the self-medication practice was $12.7 \%-95 \%$ in other developing countries. ${ }^{13-15}$ The most important reason for increase in trend of selfmedication is easy availability of all categories of medicines, OTC, prescriptions only or even schedule X drugs without prescription. It is understandable that a significant proportion of the respondents in our study used analgesics either alone or in combination with other drugs without prescription as common analgesics can be bought without prescription in the community. Most respondents gave the reason for self-medication to the fact that they felt that their complaints were minor enough for such selfcare and easy availability in urban areas where as low cost compounded by lack of access to doctors. This is a dangerous assumption as minor ailments that could easily have been managed by a physician, could easily be mismanaged through self-medication with OTC drugs. Most of the respondents from rural population attributed the reason for self-medication was non availability of doctors. This finding is at variance with other developing countries in a study conducted at Sudan where the main reason for self-medication was financial constraint. ${ }^{16}$

This study highlights the high rate of self-medication practices both in urban and rural areas and the reasons for the same. As this study was conducted in a limited population in Mandya district, generalization of the study to all the population cannot be done, and it requires large study in all districts of Karnataka with adequate sampling methods. In our study, we focused on the self-medication practice on prevalence, pattern perception, and reasons for using it. Majority of the respondents practiced selfmedication using drugs such as analgesics, antigastric agents, and antibiotics used either alone or in combination. The main reasons identified for selfmedication were their assessment of their ailment as being minor and financial constraint and non-availability of doctors in rural areas. Health-care providers should educate patients on the dangers of self-medication. Such messages should be extended to the community at large periodically by government health ministry/authorities.
Government should enforce relevant and strict legislation, which limits the sales of drugs without prescription to only few relatively harmless OTC ones. There is need to create awareness about existing health facilities so that patients will know where to go, when the need arises thereby minimizing the potential resort to self-medication.

\section{ACKNOWLEDGMENTS}

The author would like to thank all the participants in the study.

\section{Funding: No funding sources Conflict of interest: None declared \\ Ethical approval: The study was approved by the Institutional Ethics Committee}

\section{REFERENCES}

1. MC GuptaWhat is the legal aspects of over-thecounter sale of allopathic medicines? Indian Journal of Clinical Practice. 2013;23:12.

2. Cooper RJ. Over-the-counter medicine abuses a review of the literature. Journal of Substance Use. 2013;18(2):82-107.

3. Hussain A, Khanum A. Self-medication among university students of Islamabad, Pakistan- a preliminary study. Southern Med Review. 2008;1(1):14-6.

4. Ali SE, Ibrahim MIM, Palaian S. Medication storage and self-medication behaviour amongst female students in Malaysia. Pharmacy Practice. 2010;8(4):1-7.

5. Wazaifya M, Shieldsb E, McElnayb H, McElnayb JC. Societal perspectives on over-the-counter (OTC) Medicines. Family Practice. 2005;22:170-6.

6. Bang S, Sontakke S, Thawani V. Pre and postinterventional pattern of self-medication in three common illnesses in staff of a tertiary hospital. Indian Journal of Pharmacology. 2011;43(3):275-7.

7. Shankar PR, Partha P, Shenoy N. Self-medication and non-doctor prescription practices in Pokhara valley, Western Nepal; a questionnaire based study. BMC Fam Pract. 2002;3:17.

8. Choonara I, Gill A, Nunn A. Drug toxicity and surveillance in children. $\mathrm{Br} \mathrm{J}$ Clin Pharmacol. 1996;42:407-10.

9. Lam CL, Catarivas MG, Munro C, Lauder IJ. Selfmedication among Hong Kong Chinese. Soc Sci Med. 1994;39(12):1641-7.

10. Sanghani S, Zaveri HG, Patel VJ. Self-medication: prevalence and pattern in urban community. J Pharmacovigilance Drug Saf. 2008;5:95-8.

11. Heineck I, Schenkel EP, Vidal X. Non-prescription drugs in Brazil. Rev Panam Salud Publica. 1998;3:385-91

12. Hughes L, Whittlesea C, Luscombe D. Patients knowledge and perceptions of the side- effects of OTC medication. J Clin Pharm Ther. 2002;27(4):243-8. 
13. Dineshkumar B, Raghuram TC, Radhaiah G, Krishnaswamy K. Profile of drug use in urban and rural India. Pharmacoeconomics. 1995;7(4):332-46.

14. Kasilo OJ, Nhachi CF, Mutangadura EF. Epidemiology of household medications in urban Gweru and Harare. Cent Afr J Med. 1991;37(6):16771.
15. Omolase CO, Adeleke OE, Afolabi AO, Afolabi OT. Self-medication amongst general outpatients in a Nigerian community hospital. Ann Ib Postgrad Med. 2007;5(2):64-7.

16. Awad AI, Eltayeb IB, Capps PA. Self-medication practices in Khartoum state, Sudan. Eur J Clin Pharmacol. 2006;62(4):317-24.

Cite this article as: Hanumantharayappa NB, Siddaiah SN. Use of over the counter drugs in urban and rural populations of Mandya district: a cross-sectional study. Int J Basic Clin Pharmacol 2016;5:1617-21. 